\title{
Ni calco ni copia. Antología de la filosofía peruana contemporánea
}

\author{
No trace or copy. Anthology of Contemporary Peruvian \\ Philosophy
}

Nem calco, nem cópia. Antologia da filosofia peruana contemporânea (tradução nossa).

Rubén Quiroz Ávila. Editorial Solar Ediciones, Colección El barro pensativo 5, Lima, 2019, 310 págs.

Maricielo Hilda Gargate Motta*

Rubén Quiroz inicia su antología con una breve introducción, en la cual expone los tópicos en los que se ha basado para historiar la filosofía peruana contemporánea. Allí afirma que "pensar en español se vuelve un atrevimiento" en un contexto en el que la filosofía se hace en tierras y lenguas extranjeras. Expone a continuación una breve biografía académica de los distintos y distinguidos filósofos antologados, iniciando por Francisco Miró Quesada y terminando con

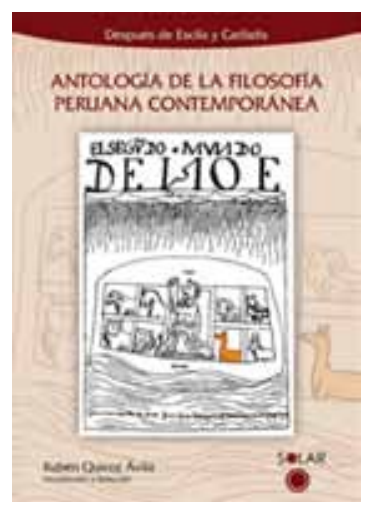
Zenón Depaz, como quien hace una ruta de la filosofía peruana más universalista hasta llevarnos al centro de la misma: una reflexión filosófica sobre el mundo andino. Tenemos, pues, una ruta que recorre las diferentes expresiones del filosofar peruano hasta encauzarla hacia su propia y más original vertiente.

\footnotetext{
* Peruana. Estudiante de la Escuela Profesional de Filosofía, Universidad Nacional Mayor de San Marcos, Miembro del Parlamento Andino Universitario Quinta Comisión Derechos Humanos, Desarrollo Social y Participación Ciudadana, Universidad Nacional Mayor de San Marcos. Contacto: maricielo.gargate@unmsm.edu.pe ORCID: https://orcid.org/0000-0001-6986-821X
} 
El primer trabajo compilado es el texto "Universalismo y latinoamericanismo", de Francisco Miró Quesada, en el que el autor muestra las confrontaciones que han experimentado dos posturas filosóficas, a saber, el universalismo como el filosofar sobre los grandes temas de la filosofía, y el latinoamericanismo como el meditar sobre nuestra propia realidad. En este sentido, cada una tiene un concepto distinto de lo que es la autenticidad filosófica. El mismo autor, a medida que relata su paso de una a la otra postura, hace un diagnóstico de ambas. De la última resalta que muestra la relación de la filosofía con el mundo social en la que se sitúa, y afirma la necesidad de un cambio en la metodología dado los acontecimientos históricos; de la primera destaca la capacidad de síntesis a la que llegaron los filósofos analíticos, quienes contribuyeron grandemente en sus campos de investigación. Teniendo tales antecedentes, Miró Quesada ve un gran desafío para las nuevas generaciones, que consiste en hacer que la filosofía se funde - quizá una autofundamentación — de nuevo, con el objetivo de avanzar hacia una visión sistemática y sintética de la realidad, la cual, opina, ya ha empezado.

Continúa la antología con el artículo de Augusto Salazar Bondy "El comienzo del filosofar", en el cual el filósofo de la reforma educativa desarrolla la máxima kantiana: no se puede aprender filosofía sino a filosofar. Para el proceso de iniciación filosófica, Salazar Bondy recomienda consultar diversos textos canónicos de autores como Platón o Berkeley, así como manuales, historias de la filosofía, diccionarios filosóficos y ensayos. Todo esto con el objetivo de incrementar el aprendizaje, pero no repetir una doctrina, sino llegar a una nueva forma de pensar gracias tanto a la meditación personal como a la admiración.

Continuamos nuestro recorrido con el artículo "Repensando la tradición nacional", de David Sobrevilla. El maestro caracteriza a la filosofía en América Latina como un caso de filosofía heterogénea, por lo que se ve en la necesidad de repensar la tradición occidental. Afirma que es el anatopismo la causa de la falta de tradición de una filosofía nacional, lo que trae como consecuencia la preferencia de una filosofía universalista en contraste de una regionalista o liberacionista. Anima a sus lectores a repensar la propia tradición filosófica y a hacer un ejercicio de apropiación y cuestionamiento de la tradición occidental, para lo que brinda el método que utilizó en ejercicio del mismo proyecto. 
Sigue el artículo de Edgard Montiel titulado "El Inca Garcilaso y la independencia de las Américas", en el que resalta el papel que tuvieron los Comentarios Reales en la formación de conceptos importantísimos para sus lectores durante diferentes épocas; sírvase de ejemplo el concepto de "derecho natural" que apoyaba la fundamentación jurídicoideológica de diversos movimientos sociales, así como al proceso de Independencia de las colonias. Garcilaso, junto a otros grandes personajes, como Bartolomé de Las Casas o Carlos de Siguenza y Góngora, iniciarían una crítica a la forma de gobierno que ejercía España, lo cual dio paso a un naciente nacionalismo que posteriormente influenció en los diversos movimientos independentistas. A la par, el catedrático sanmarquino demuestra la importancia del Inca Garcilaso en el proceso de construcción de una América independiente.

El libro continúa con el ensayo "En torno a la identidad nacional", de María Luisa Rivara, una de las fundadoras de la Sociedad Peruana de Filosofía, en el que se desarrolla el tema de la identidad nacional. Rivara argumenta que dicha identidad se busca a través de una razón unificadora, capaz de dilucidarla tal como constituida por una triple manifestación: pluriculturalismo, plurietnismo y plurilingüismo. Tales características provienen de una época prehispánica y perviven hasta nuestros días. Concluye afirmando que son estas características las que constituyen una identidad nacional actual, y que, de aceptarlas, abriría puertas hacia a una nueva estructura de pensamiento.

Luego, José Ignacio López Soria, en su artículo "El principio interculturalidad y la filosofía de la plenitud", nos invita a aceptar la interculturalidad y, con ésta, a pensar la actualidad con categorías conceptuales que no sean portadoras de algún tipo de violencia, ya sea epistémica, simbólica o práctica. De-construir ese cuerpo categorial y dirigirnos a pensar la vida humana en términos de plenitud es su principal prioridad. En este proyecto incluye, por ejemplo, considerar a la naturaleza como compañera de viaje del hombre y no como su sierva o instrumento; así como definir al hombre como ser-con-el-mundo en contraste con el ser-en-el-mundo.

José Carlos Ballón continúa esta lista de académicos con su ensayo "Ética, modernidad y autoritarismo en el Perú actual: ¿vigilar y castigar?", en el que se puede apreciar la problemática acerca de la corrupción muy de cerca. A su vez, dentro de la vida del ciudadano peruano, 
investiga la real normatividad pragmática que erigió la civilización y la cultura moderna, para contrastarla con las pretensiones de modernización de la vida peruana.

Teresa Arrieta contribuye con "Ética ambiental: del dominio al respeto a la naturaleza", un texto bien cuidado que nos habla de una ética del hombre en relación con la naturaleza. En este marco, el tópico que nos guía es la bioética. Mediante ella se podrá encuadrar cabalmente las actitudes que tiene el hombre ante su medio ambiente; se le dará privilegio, antes que al mercado, a la comunión del hombre con la naturaleza. Se tiende por eso hacia una armonía que implique el desenvolvimiento del hombre dentro de la naturaleza y no en contraposición con ella.

Juan Abugattás, gran maestro sanmarquino, con su "Latinoamérica: el reto de las redefiniciones" retoma un problema debatido y estudiado por varios autores de esta antología, que es el de analizar el concepto de "Latinoamérica". Este, afirma Abugattás, ha sido una invención occidental en un afán por construir una "esencia" de lo americano, sumido en prejuicios esencialistas en función de la raza, lengua o cultura. Abugattás nos invita a reflexionar sobre la real condición del hombre latinoamericano y, bajo este llamado a la autenticidad, desarrollar categorías propias que abran las puertas a una nueva comprensión del hombre latinoamericano, con el fin de construir una identidad propia.

Acto seguido, Augusto Castro en "La filosofía entre nosotros. Cinco siglos de filosofía en el Perú" busca hacer una historia de la filosofía propia de los peruanos, y apunta a integrar dos perspectivas que tradicionalmente se han visto como contrarias: la filosofía universalista y la regionalista. El destacado latinoamericanista postula que tanto la una como la otra se apoyan en el desarrollo de la filosofía peruana y, bajo esta premisa, elabora su texto que lleva el mismo título.

Enseguida se encuentra antologado el trabajo de Pablo Quintanilla - respetado estudioso de la filosofía del lenguaje, de la filosofía de la mente y de la filosofía latinoamericana-, un ensayo que ahonda en las condiciones de posibilidad de comunicación con el otro y pretende formular un giro a la manera cómo se ha entendido la racionalidad desde la modernidad, dirigido hacia la transformación de nuestra manera de concebir el lenguaje. El argumento de Quintanilla 
despliega la posibilidad de enfocar la racionalidad no como criterio universal e imperialista, sino como aquello que corresponde al intérprete asignar al agente (su interlocutor, el emisor del mensaje podría decirse), una vez que el primero haya construido/simulado para el segundo una serie de estados mentales que conformarían su sistema de creencias. Este sistema de creencias es, a su vez, algo que el intérprete elabora - a manera de una hermenéutica empática- solo cuando logra ponerse en el lugar del agente y establece criterios de verdad basados en los que aquél cree que este último tendría. La apuesta es, entonces, focalizar una creencia en relación con el sistema antes conformado y detectar si posee los criterios de un lenguaje intencional; es decir, si es coherente dentro de su propia totalidad: así la racionalidad emerge como una propiedad relacional. De lo que se trata, concluye, no es de una fusión de horizontes sin más, ni de un relativismo ingenuo, sino de una construcción mutua de los estados mentales o significados en el mismo proceso de la comunicación, en el que tanto intérprete como agente aportan subjetividades y sus criterios de objetividad.

El recorrido por la antología de Quiroz nos lleva finalmente a la filosofía andina, donde encontramos a dos interesantes autores: Víctor Mazzi Huaycucho y Zenón Depaz Toledo. El primero, con su ensayo "Kay, pacha, yachay. La reflexión y el saber en el Tawuantinsuyo", realiza un análisis exhaustivo sobre los términos aludidos y su importante significado en el mundo andino, específicamente en los hamut'aq del Tawantinsuyu. Muestra que "kay" designa una forma categorial de existencia, "yachay" es una reflexión que comprende las condiciones del conocimiento, y "pacha” indica la construcción de una definición de naturaleza o universo. Este último término también será objeto de análisis del segundo autor en su "Experiencia cósmica y dinámica social en el manuscrito de Huarochirí". El término “pacha”, según Depaz Toledo, se puede traducir como Madre Tierra, que es lo que engendra y de donde surgen los frutos con los que uno se alimenta tanto material como espiritualmente. Tiene, por lo tanto, una fuerte connotación de algo sagrado, que conecta y sostiene el mundo, y a nosotros junto a él. La "pacha", pues, tiene un gran alcance ontológico, connota totalidad y plenitud, y esta es la razón de una experiencia vívida del término; en este sentido, la "pacha" se manifiesta en la claridad de lo fenoménico $\mathrm{y}$, sin embargo, fenoménicamente lo excede. De esta forma, el mundo 
viene a ser un tejido relacional constituido por la dimensión sagrada desplegada bajo una constitución orgánica, y el ser humano forma parte de esta experiencia del mundo.

La antología de Rubén Quiroz nos muestra un recorrido por la filosofía peruana contemporánea, en la que, sin embargo, tenemos aún muchos autores más que integrar y conocer, que me gustarían se pudieran añadir en una siguiente antología. Sobre la estructura del texto, considero que los autores, los textos elegidos de los mismos y su orden han sido establecidos inteligentemente, lo cual brinda una sensación de cohesión y diálogo mientras se pasa de la lectura de uno a otro. Un detalle que considero práctico para una futura edición, y del que esta carece, es incorporar en el índice el nombre de los ensayos de cada autor. Fuera de estos pequeños detalles tipográficos o de imprenta, es un libro que vale la pena que todo filósofo peruano y latinoamericano consulte. 